\title{
How should laboratories measure mycobacterial load?
}

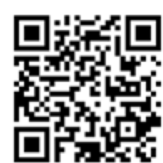

The ability to accurately and reproducibly quantify mycobacteria in a cost-effective manner is essential for both basic and applied tuberculosis (TB) research. In immunology, laboratory-based experiments are frequently performed to compare the effect of regulatory T-cells on mycobacterial kill under different conditions. ${ }^{[1]}$ In diagnostics research, bacilli in different specimens are often quantified to calculate the required limit of detection ${ }^{[2]}$ or investigate whether in paucibacillary specimens (e.g. pleural fluid) a biomarker-based approach may be optimal. ${ }^{[3,4]}$ In clinical research, the quantity of mycobacteria (bacillary load) is a predictor of disease severity, ${ }^{[5]}$ clinical outcome, ${ }^{[6,7]}$ and risk of transmission. ${ }^{[8-10]} \mathrm{A}$ variety of tools exist for quantifying bacillary load in specimens. However, there are few data about their comparative utility and cost.

In this edition of the South African Respiratory Journal, Pooran and colleagues compare the cost of five methods (BACTEC MGIT 960 culture, manual colony counts on solid agar, radio-labelled uracil incorporation assays, luciferase reporter construct bioluminescence, and the Xpert MTB/RIF real-time PCR test) for the determination of mycobacterial load in a research setting. This is a follow-on study to their previous publication, ${ }^{[11]}$ which evaluated the turnaround time, limit of detection, dynamic range, reproducibility and discriminative ability of each technique.

Collectively, these two studies show that automated liquid culture is the most sensitive technique $(\sim 10 \mathrm{CFU} / \mathrm{mL})$, with the highest reproducibility and discriminatory power, for a cost of approximately R240 per sample. The luminescence assay, which requires inserting a gene into Mycobacterium tuberculosis cells and quantifying the intensity of the expressed luminescent protein, was rapid and the least costly technique (R155), as it required the least hands-on time, but had a higher limit of detection than liquid culture ( 100 v. $10 \mathrm{CFU} / \mathrm{mL}$ ). Conversely, the radio-labelled uracil assay and the automated Xpert MTB/RIF assay were the most expensive methods (R349 and R388, respectively), with costs chiefly driven by expensive capital equipment and, in the case of Xpert MTB/RIF, the additional cost of the cartridge. Although both tests were able to provide results in hours, the uracil assay had a limit of detection 10-fold higher than Xpert MTB/ RIF ( 1 000 v. $100 \mathrm{CFU} / \mathrm{mL})$ and Xpert MTB/RIF was more userfriendly. Although sensitive $(<10 \mathrm{CFU} / \mathrm{mL})$, manual colony counts were expensive (R385), and the results are only available after several weeks.

The authors conclude that the choice of test depends on the application. Where highly sensitive, accurate results are required and time is not an issue, liquid culture is suitable. If results are required within hours, a small offset in sensitivity is acceptable, and the extra expense affordable, then more rapid, user-friendly assays such as
Xpert MTB/RIF are ideal. Finally, it is important to note that in clinical settings where TB diagnostics are routinely performed, information about mycobacterial load is generated from both liquid culture (timeto-positivity) and Xpert MTB/RIF (cycle threshold values).

\section{References}

1. Semple PL, Binder AB, Davids M, Maredza A, van Zyl-Smit RN, Dheda K. Regulatory $\mathrm{T}$ cells attenuate mycobacterial stasis in alveolar and blood-derived macrophages from patients with tuberculosis. Am J Respir Crit Care Med 2013;187(11):1249-1258. [http://dx.doi.org/10.1164/rccm.201210-1934OC]

2. Theron G, Peter J, Calligaro G, et al. Determinants of PCR performance (Xpert MTB/ RIF), including bacterial load and inhibition, for TB diagnosis using specimens from different body compartments. Sci Rep 2014;4:5658. [http://dx.doi.org/10.1038/ srep05658]

3. Meldau R, Peter J, Theron G, et al. Comparison of same day diagnostic tools including Gene Xpert and unstimulated IFN-gamma for the evaluation of pleural tuberculosis: A prospective cohort study. BMC Pulm Med 2014;14:58. [http://dx.doi. org/10.1186/1471-2466-14-58]

4. Pandie S, Peter J, Kerbelker Z, et al. Diagnostic accuracy of quantitative PCR (Xpert MTB/RIF) for tuberculous pericarditis compared to adenosine deaminase and unstimulated interferon $\gamma$ in a high burden setting: A prospective study. BMC Med 2014;12:101. [http://dx.doi.org/10.1186/1741-7015-12-101]

5. Theron G, Zijenah L, Chanda D, et al. Feasibility, accuracy, and clinical effect of pointof-care Xpert MTB/RIF testing for tuberculosis in primary-care settings in Africa: A multicentre, randomised, controlled trial. Lancet 2013;383(9915):424-435. [http:// dx.doi.org/10.1016/S0140-6736(13)62073-5]

6. Bark CM, Thiel BA, Johnson JL. Pretreatment time to detection of Mycobacterium tuberculosis in liquid culture is associated with relapse after therapy. J Clin Microbiol 2012;50(2):538. [http://dx.doi.org/10.1128/JCM.06193-11]

7. Pheiffer C, Carroll N, Beyers N, et al. Time to detection of Mycobacterium tuberculosis in BACTEC systems as a viable alternative to colony counting. Int J Tuberc Lung Dis 2008;12(7):792-798.

8. Fennelly KP, Martyny JW, Fulton KE, Orme IM, Cave DM, Heifets LB. Coughgenerated aerosols of Mycobacterium tuberculosis: A new method to study infectiousness. Am J Respir Crit Care Med 2004;169(5):604-609. [http://dx.doi. org/10.1164/rccm.200308-11010C]

9. Theron G, Pinto L, Peter J, et al. The use of an automated quantitative polymerase chain reaction (Xpert MTB/RIF) to predict the sputum smear status of tuberculosis patients. Clin Infect Dis 2012;54(3):384-348. [http://dx.doi.org/10.1093/cid/cir824]

10. Hanrahan CF, Theron G, Bassett J, Dheda K, Scott L, Stevens W, et al. Xpert MTB/RIF as a measure of sputum bacillary burden: Variation by HIV status and immunosuppression. Am J Respir Crit Care Med 2014;189(11):1426-1434. [http:// dx.doi.org/10.1164/rccm.201312-2140OC]

11. van Zyl-Smit RN, Binder A, Meldau R, et al. Comparison of quantitative techniques including Xpert MTB/RIF to evaluate mycobacterial burden. PloS One 2011;6(12):e28815. [http://dx.doi.org/10.1371/journal.pone.0028815]

\section{Grant Theron}

DST/NRF of Excellence for Biomedical Tuberculosis Research Medical Research Council Centre for Molecular and Cellular Biology, Division of Molecular Biology and Human Genetics, Faculty of Medicine and Health Sciences, Stellenbosch University, Tygerberg, South Africa

Lung Infection and Immunity Unit, Department of Medicine, University of Cape Town, South Africa

S Afr Resp J 2015;21(3):54. DOI:10.7196/10.2015.v21i3.54 